\title{
ФИНАНСОВАЯ СИСТЕМА РОССИИ КАК БАЗОВАЯ КАТЕГОРИЯ ФИНАНСОВОЙ НАУКИ И НАУКИ ФИНАНСОВОГО ПРАВА: ПОДХОДЫ К ОПРЕДЕЛЕНИЮ
}

\begin{abstract}
АНнотАция. Статья посвящена исследованию понятия «финансовая система», представляющего собой одну из базовых категорий как финансовой науки, так и науки финансового права. Анализ научного материала позволил выделить четыре основных подхода, использованных в экономических и юридических работах при определении содержания финансовой системы. При этом выделено широкое и узкое понимание отдельных звеньев финансовой системы - бюджетных отношений, финансов хозяйствующих субъектов, с учетом чего предложено два варианта интерпретации структуры финансовой системы. Рассмотрены функциональный подход, характеризующий финансовую систему как совокупность сфер (или звеньев) финансовых отношений, материальный подход к пониманию финансовой системы как совокупности фондов денежных средств, институциональный подход, основанный на включении в состав финансовой системы институтов, осуществляющих финансовые операции и управление в данной сфере, и смешанный подход. Сделан вывод о регулировании финансовой системы нормами как финансового права, так и иных отраслей права.
\end{abstract}

кЛючЕВЫЕ СЛОВА. Финансовая система; бюджетные отношения; финансы хозяйствующих субъектов; предмет финансового права.

ИНФОРМАЦИЯ О СТАТЬЕ. Дата поступления 30 декабря 2015 г.; дата принятия к печати 25 января 2016 г.; дата онлайн-размещения 31 марта 2016 г.

ФИНАНСИРОВАНИЕ. Государственное задание № 2014/52 на выполнение работ в сфере научной деятельности в рамках базовой части проекта № 597 «Разработка методологии финансового обеспечения социально значимых расходов» (номер госрегистрации в ФГАНУ ЦИТиС 01201458899).

Yu. V. Pyatkovskaya

Baikal State University,

Irkutsk, Russian Federation

\section{RUSSIA'S FINANCIAL SYSTEM AS A BASIC CATEGORY OF FINANCIAL SCIENCE AND SCIENCE OF FINANCIAL LAW: APPROACHES TO DEFINITION}

\begin{abstract}
The article is devoted to investigating the concept «financial system» which presents one of the basic categories of both the financial science and the science of financial law. Analysis of scientific material allows to identify four major approaches used in economic and juridical works in defining the content of the financial system. At that, it specifies broad and narrow understanding of separate chains of the financial system budget relations, finance of economic entities with allowance of which it offers two variants of interpretation of the financial system structure. It considers a functional approach which characterizes the financial system as an aggregate of spheres (or links) of financial relations; a material approach to understanding the financial system as an aggregate of monetary funds; an institutional approach based on inclusion of institutions, that perform financial operations and management in this sphere, into the makeup of the financial system, and a mixed approach. A conclusion is made about regulating the financial system by the provisions of both the financial law and other branches of the jurisprudence.
\end{abstract}

(C) Ю. В. Пятковская, 2016

\section{Baikal Research Journal}


KEYWORDS. Financial system; budget relations; finance of economic entities; subject of financial law.

ARTICLE INFO. Received December 30, 2015; accepted January 25, 2016; available online March 31, 2016.

FINANCING. The work was financially supported by the state task on performing state works on scientific activities No. 2014/52 in the framework of the basic part of the project «Development of methodology for financial support of socially significant costs» No. 597 (state registration number in FSRI CITIS 01201458899).

На сегодняшний день понятие и содержание финансовой системы России не имеет нормативного закрепления и разрабатывается представителями как финансовой науки, так и специалистами по финансовому праву. Традиция рассматривать в единстве правовые и экономические вопросы зародилась еще дореволюционными правоведами и активно поддерживается современными учеными-юристами, проводящими в своих правовых исследованиях экономический анализ рассматриваемых явлений и категорий. Как совершенно справедливо подчеркивает Е. Ю. Грачева, рассмотрение правовой формы нельзя отрывать от экономического содержания явления, облекаемого в эту правовую форму, что позволит всесторонне, комплексно, четко отразить в праве потребности экономического развития страны [1, с. 21-22].

При исследовании финансовой системы в работах как финансистов, так и юристов выделяются четыре основных подхода к ее определению.

Функциональный подход (в юридических работах именуемый экономическим), характеризующий финансовую систему как совокупность сфер (или звеньев) финансовых отношений.

Так, Г. М. Колпакова финансовую систему определяет как совокупность блоков, звеньев, подзвеньев финансовых отношений: государственные финансы, местные финансы, финансы юридических и физических лиц [2, с. 150-151]. Как совокупность различных сфер финансовых отношений, в процессе которых образуются и используются различные денежные фонды, определяют финансовую систему и в учебнике «Финансы и кредит» под редакцией М. В. Романовского и Г. Н. Белоглазовой, которые относят к таковым сферам финансы хозяйствующих субъектов (коммерческих и некоммерческих организаций, финансовых посредников) и государственные и муниципальные финансы (бюджетная система и государственный кредит) [3, с. 36]. Данный подход к определению финансовой системы прослеживается в работах и иных представителей финансовой науки [4, с. 176-177].

Опираясь на разработки финансовой науки, в работах по финансовому праву также уделяется внимание категории «финансовая система». Е. А. Ровинский, являясь автором соответствующего параграфа в учебнике «Финансовое право» (1971), ограничился воспроизведением мнений финансистов по поводу структуры финансовой системы, выделяя в ней финансы государственных предприятий и отраслей хозяйства; общегосударственные, централизованные финансы, охватывающие государственный бюджет, государственное имущественное и личное страхование и государственное социальное страхование; кредит [5, с. 14]. М. В. Карасева, говоря о финансовой системе, подчеркивает, что финансово-правовая наука не может дополнять или каким-то образом изменять содержание этой финансово-правовой категории, а лишь заимствовать эту категорию в своих целях в том содержании, которое дано экономической наукой [6, с. 19-20].

Однако преимущественно специалисты по финансовому праву проводят собственные исследования обозначенного вопроса, подавляющее большинство при этом поддерживают функциональный подход, рассматривая финансовую систему как совокупность следующих финансовых институтов (совокупность однородных экономических финансовых отношений): бюджетные отношения, отношения по

\section{Baikal Research Journal}


формированию и использованию государственных внебюджетных фондов, финансы предприятий, организаций, учреждений, кредитные отношения (государственный, муниципальный, банковский кредит), страховые отношения [7, с. 20; 8, с. 20-21].

Однако представленная структура финансовой системы не бесспорна. Представляется необходимым высказать следующие соображения:

1. К бюджетным отношениям следует также относить отношения, связанные с функционированием государственных внебюджетных фондов, являющихся частью бюджетной системы России, в соответствии со ст. 6, 10 Бюджетного кодекса Российской Федерации.

2. Бюджетные отношения можно рассматривать в двух значениях. В широком понимании к бюджетным отношениям следует относить совокупность всевозможных отношений по наполнению фондов бюджетной системы Российской Федерации как их доходных источников, как и путем использования кредитных ресурсов, а также отношения по распределению и использованию фондов бюджетной системы Российской Федерации как путем финансирования, так и путем кредитования. Иными словами, при таком понимании бюджетные отношения будут включать государственный и муниципальный кредит.

Выделяя государственный и муниципальный кредит в качестве отдельного звена финансовой системы, следует говорить поэтому о понимании бюджетных отношений в узком смысле. При этом возникает необходимость ограничить бюджетные отношения как звено финансовой системы, исключив из них все возможные кредитно-заемные отношения.

3. Финансы предприятий, организаций, учреждений представляется более верным именовать финансами хозяйствующих субъектов, определяя их как отношения по поводу образования, распределения и использования фондов хозяйствующих субъектов (фондов юридических лиц и индивидуальных предпринимателей, образуемые в ходе ведения соответствующей хозяйственной деятельности). Дело в том, что деятельность индивидуальных предпринимателей в рамках национальной экономики имеет родственную экономическую природу с деятельностью организаций - они также участвуют в создании валового общественного продукта. В процессе распределительных финансовых отношений у индивидуальных предпринимателей также образуются денежные доходы и накопления, которые направляются на расширенное воспроизводство, материальное стимулирование наемных рабочих.

4. Финансы хозяйствующих субъектов можно также рассматривать в широком смысле, относя к ним все без исключения фонды, образуемые данным субъектом хозяйствования. Так, например, если субъектом хозяйствования выступает кредитная организация, то к данному звену финансовой системы следует отнести совокупность финансовых отношений по образованию, распределению и использованию таких фондов, как фонд заработной платы, фонд прибыли, амортизационный фонд, всевозможные резервные фонды и иные фонды, которые обслуживают кредитную организацию как юридическое лицо. Кроме того, к данному звену финансовой системы в этом случае будут отнесены и отношения по формированию и использованию кредитных ресурсов (так называемый кредитный фонд).

Если в качестве примера взять страховую организацию, то при широком понимании категории «финансы хозяйствующих субъектов», к таковым отнесем совокупность финансовых отношений по образованию, распределению и использованию таких фондов, обслуживающих страховую организацию, как юридическое лицо, а также отношения по формированию и использованию страхового фонда.

В узком понимании финансов хозяйствующих субъектов следует ограничиться финансами индивидуальных предпринимателей, а также финансовыми отношениями по образованию, распределению и использованию фондов, обслуживающих

\section{Baikal Research Journal}


организацию как юридическое лицо. Только в этом случае можно говорить о банковском кредите и страховых отношениях как об отдельных звеньях финансовой системы России.

5. При традиционном понимании структуры финансовой системы не ясно, куда следует относить значительный блок финансовых отношений, связанных с взиманием доходов бюджетной системы, к которым, несомненно, относятся налоговые отношения. К бюджетным отношениям (в их узком понимании) их вряд ли можно относить, поскольку о них можно говорить только с момента, когда какой-то доход зачисляется на счета Федерального казначейства. В связи с этим возникает потребность в выделении отдельного звена финансовой системы - финансовых отношений, связанных с взиманием доходов бюджетной системы.

6. Отдельными авторами выделяется такое звено финансовой системы, как финансы домашних хозяйств [4, с. 177], финансы физических лиц [2, с. 150-151; 9 , с. 17], финансы населения [10, с. 33-34], что вызывает возражения. Следует согласиться с Е. В. Покачаловой в том, что финансы, направленные на формирование и использование финансовых ресурсов в фондовой форме, не характерны для физических лиц, удовлетворяющих свои личные потребности [11, с. 83]. Основное предназначение финансов заключается в распределении валового общественного продукта в денежной форме между государством и субъектами хозяйствования, т. е. теми, кто участвовал в создании этого валового общественного продукта.

С учетом изложенного можно предложить два варианта интерпретации структуры финансовой системы как совокупности сфер и звеньев финансовых отношений.

В первом случае каждый из финансовых институтов мы рассматриваем в узком его понимании:

- бюджетные отношения;

- отношений, связанных с взиманием доходов бюджетной системы, в том числе налоговые отношения;

- финансы хозяйствующих субъектов;

- кредитные отношения (государственный, муниципальный, банковский кредит);

- страховые отношения.

Во втором случае в структуре финансовой системы можно выделить совокупность следующих финансовых институтов, принимая во внимание их широкое толкование:

- финансы централизованных фондов - как совокупность финансовых отношений по поводу образования, распределения и использования централизованных фондов (фондов бюджетной системы России), в том числе и отношения, связанные со взиманием доходов бюджетной системы;

- финансы децентрализованных фондов (финансы хозяйствующих субъектов).

Наряду с функциональным подходом к определению финансовой системы в финансовой и юридической литературе присутствует материальный подход, основанный на вещественном понимании сущности «финансов», описанном еще в конце XIX в. русскими учеными. Так, Ф. В. Мильгаузен определял финансы как вещественные ценности, выделяемые из общего (народного) имущества и передаваемые в руки правительства для достижения общих целей $[12$, с. 60$]$. В. А. Лебедев также относил к финансам натуральные государственные доходы: «все вообще средства, которые государство может иметь для выполнения своих целей, - будут ли эти средства заключаться в личных услугах граждан, или в разных вещественных материалах, капиталах, денежных сборах и пр., - все они могут быть названы финансами» $[13$, с. 36$]$. И. И. Янжул отмечал, что под финансами следует понимать совокупность материальных средств, необходимых для удовлетворения потребностей государств [14, с. 44]. Материальное значение сущности «финансов» подчеркивается и современными учеными. Так, В. М. Родионова указыва-

\section{Baikal Research Journal}


ет, что материальными носителями финансовых отношений выступают финансовые ресурсы, использование которых осуществляется через специальные фонды [15, с. 11]. О материальном значении категории финансы упоминается и в юридической литературе [16, с. 22].

С учетом приведенного материального понимания финансов, финансовую систему рассматривают также как совокупность фондов денежных средств. Так, А. З. Дадашев и Д. Г. Черник считают, что финансовую систему можно определить как совокупность финансовых ресурсов всех участников воспроизводства общественного продукта [17, с. 3].

Материальный подход к определению финансовой системы нашел поддержку и в юридической литературе. Например, В. В. Бесчеревных подчеркивал двойственную природу, указывая, что любой финансовый институт, являясь экономической категорией (системой экономических отношений), имеет определенное материальное содержание, т. е. является фондом соответствующих денежных средств [18, с. 13].

Е. В. Покачалова, наряду с иными представителями саратовской школы финансового права, при структурировании финансовой системы отправным считает материальное выражение звеньев (институтов) финансовой системы, рассматривая ее как совокупность денежных фондов, отличающихся специфическими признаками $[11$, с. 80$]$.

Нередко в работах юристов финансовая система рассматривается в материальном смысле как совокупность централизованных и децентрализованных фондов $[19$, c. 41$]$.

М. Ф. Ивлиева отмечает, что на современном этапе финансовая система государства представляет собой в материальном смысле совокупность фондов государственных денежных средств и денежных средств муниципальных образований. При этом она разграничивает понятия «финансовая система государства» и «финансовая система России», относя к последней наряду с государственными и муниципальными фондами денежные фонды иных форм собственности [20, с. 16].

Фондовый (материальный) признак при структурировании финансовой системы использован Э. Д. Соколовой, которая в структуре финансовой системы выделяет в зависимости от формы собственности три звена:

- государственные финансы, которые делятся на централизованные (федеральный бюджет, бюджеты субъектов Российской Федерации, государственные внебюджетные фонды, госкредит) и децентрализованные (фонды Банка России, иных кредитных организаций, основанных на праве государственной собственности или праве смешанной форме собственности, в части, принадлежащей государству; фонды государственных унитарных предприятий, государственных учреждений);

- местные финансы (местные бюджеты, местные внебюджетные фонды, фонды денежных средств муниципальных банков, фонды денежных средств муниципальных унитарных предприятий, муниципальных учреждений, разовые добровольные сборы населения);

- частные финансы (фонды денежных средств, создаваемые юридическими лицами и иными организациями, функционирующими на праве частной собственности, а также денежные средства физических лиц, в том числе индивидуальных предпринимателей, действующих без образования юридического лица) $[9$, с. $17 ; 21$, c. 26$]$.

Позднее Э. Д. Соколова выделила четвертый элемент финансовой системы иные финансы, отнеся к ним фонд страхования вкладов, собственником которых выступает соответствующая государственная корпорация, при этом сам фонд расходуется в публичных целях [22, с. 51].

\section{Baikal Research Journal}


Особо следует подчеркнуть, что именно в материальном значении финансовая система понималась в Законе РСФСР «Об основах бюджетного устройства и бюджетного процесса в РСФСР ${ }^{1}$. В ст. 14 указанного закона, посвященной взаимоотношениям бюджетов с другими элементами финансовой системы, устанавливалось, что бюджетная система РСФСР является частью финансовой системы РСФСР, включающей в себя финансы самостоятельных юридических и физических лиц.

Таким образом, материальный подход предполагает структурирование финансовой системы с учетом фондового критерия. Поскольку финансы материализуются в виде фондов денежных средств, финансовая система может быть представлена как совокупность централизованных и децентрализованных денежных фондов, которые могут находиться в государственной, муниципальной или частной собственности. Наряду с этим можно выделить и иные классификационные критерии структурирования финансовой системы как совокупности денежных фондов. Так, с учетом интереса, который преследуется при образовании, распределении и использовании фонда, финансовая система может быть представлена как совокупность публичных и частных фондов. Учитывая право собственности, финансовую систему можно рассматривать как совокупность государственных, муниципальных и частных фондов.

Институииональный подход к структурированию финансовой системы основывается на включении в состав финансовой системы институтов, осуществляющих финансовые операции и управление в данной сфере. При этом несколько различается состав финансовой системы в экономической и юридической литературе.

По утверждению 3. Боди и Р. Мертона, финансовая система включает в себя рынки, посредников, фирмы, предоставляющие финансовые услуги, и другие институты, с помощью которых домохозяйства, частные компании и правительственные организации реализуют принимаемые ими финансовые решения [23, с. 62$]$. По мнению Г. В. Крафт и И. П. Скобелковой, финансовая система представляет собой совокупность финансовых организаций (учреждений) и финансовых рынков, обеспечивающих с помощью различных финансовых инструментов формирование и использование денежных средств государства, организаций и населения [24, с. 32]. В финансовой литературе встречается толкование финансовой системы как совокупности хозяйствующих субъектов (финансовых учреждений), осуществляющих финансовое посредничество и вспомогательные виды деятельности [25, с. 9].

В юридической литературе также встречается и институциональный подход к пониманию финансовой системы. Указывая, что государство не может осуществлять финансовую деятельность непосредственно, институциональный механизм рассматривается как финансовая система государства [19, с. 49]. Так, В. М. Мандрица, И. В. Рукавишникова, Д. Н. Дружинин финансовую систему описывают как совокупность финансовых институтов, государственных органов и учреждений, осуществляющих в пределах своей компетенции финансовую деятельность [26, с. 25-27].

Как показал проведенный анализ, экономисты, придерживающиеся такого подхода, к элементам финансовой системы прежде всего относят различные фирмы, функционирующие на финансовых рынках и оказывающие финансовые услуги. Юристы же рассматривают в данном случае финансовую систему как совокупность публичных органов, осуществляющих финансовую деятельность государства. Этот подход вряд ли можно признать оправданным, поскольку в данном случае речь

${ }^{1}$ Об основах бюджетного устройства и бюджетного процесса в РСФСР : закон РСФСР от 10 окт. 1991 г. № 1734-1 (изм. от 10 июля 1996 г.) // Ведомости Съезда народных депутатов и Верховного Совета РСФСР. 1991. № 46, ст. 1543 (утратил силу).

\section{Baikal Research Journal}

электронный научный журнал Байкальского государственного университета 
должна идти о системе органов, осуществляющих финансовую деятельность, а не о финансовой системе. Как в финансовой, так и в юридической литературе неоднократно высказывалась крайне негативная его оценка [3, с. 36 ; 18, с. 13$]$.

В специализированной литературе также часто встречаются определения финансовой системы, представляющие собой некий синтез приведенных ранее критериев к структурированию финансовой системы, т. е. так называемый слешанный подход. Так, А. С. Нешитой относит к звеньям финансовой системы государственные и местные финансы, финансы хозяйствующих субъектов, страхование, кредитно-банковскую систему (которую определяет как совокупность банков и иных кредитных учреждений страны), а также систему государственных финансовых органов [27, с. 24]. Т. Г. Ржевская к элементам финансовой системы относит государственные финансы, финансы хозяйствующих субъектов, государственные кредитные учреждения (в том числе Банк России), систему коммерческих банков, денежный рынок, фондовый рынок, внешний долг, государственные финансовые резервы, бюджетную политику [28, с. 21]. Г. В. Комарова определяет финансовую систему государства как единый, характеризующийся целостностью составляющих его элементов, их взаимозависимостью и взаимообусловленностью комплекс финансовых институтов и соответствующих им правоотношений, управомоченных субъектов, процедур осуществления финансовой деятельности, функционирование которого регулируется нормами права, устанавливающими юридические средства формирования, распределения и организации использования публичных денежных фондов [29, с. 7].

Комментируя приведенный подход, следует поддержать С. В. Запольского, который считает, что, исходя из постулата об однородности элементов, составляющих систему, логично было бы допустить, что финансовая система должна строиться из устойчивых типизированных видов экономических отношений [30, с. 26]. Нецелесообразно в структуре финансовой системы выделять элементы одновременно по разным классификационным критериям.

При отсутствии всякого единообразия в понимании финансовой системы нередко высказываются предложения о законодательном регулировании как понятия, так и состава финансовой системы [9, с. 25; 11, с. 93-94].

Однако вряд ли можно согласиться с целесообразностью такого шага. Регулирующее воздействие закона не определяется необходимостью единообразного понимания «сложной экономической категории, имеющей огромное значение для развития общества и государства» [9, с. 25]. Как совершенно справедливо отмечает Н. А. Саттарова, поиск путей совершенствования действующего финансового законодательства (в том числе и в части закрепления новых понятий) должен соотноситься с такой категорией, как эффективность, поскольку правовое регулирование должно обеспечить достижение конкретных результатов, на которые оно направлено [31, с. 93-94]. Задача законодателя заключается в том, чтобы закрепить адекватные правовые формы объективно существующих финансовых отношений, а не определять экономические категории.

Несмотря на разрозненность подходов к определению финансовой системы, не вызывает сомнения тот факт, что финансовые отношения регулируются правом. Как совершенно справедливо указывают в совместной работе Е. Ю. Грачева и О. Н. Горбунова, каждое из звеньев финансовой системы обеспечивается соответствующим правовым институтом [32, с. 10]. Право всегда опосредует общественные отношения, возникающие между различными звеньями финансовой системы, т. е. в процессе ее функционирования, из чего Э. Д. Соколова заключает, что финансовая система является и правовой категорией [22, с. 35]. При этом важно понять, к какой отрасли права будут отнесены правовые институты, регулирую-

\section{Baikal Research Journal}


щие звенья финансовой системы. Нередко все эти институты без исключения относят к числу финансово-правовых институтов [33, с. 128], с чем вряд ли можно согласиться.

Как известно, предметом финансового права как отрасли права является финансовая деятельность государства и местного самоуправления, представляющая собой образование, распределение, использование денежных фондов государства и местного самоуправления. Общественные экономические отношения, возникающие в ходе осуществления финансовой деятельности государства, без сомнения, имеют финансовую природу, охватываются звеньями финансовой системы России. Однако данные отношения - лишь разновидность финансовых, включающих наряду с обозначенными также отношения, возникающие в ходе осуществления финансовой деятельности (деятельности по формированию, распределению и использованию денежных фондов) частных хозяйствующих субъектов. Таким образом, финансовая система, представляющая собой не только экономическую, но и правовую категорию, регулируется наряду с финансовым правом иными отраслями права.

\section{Список использованной литературы}

1. Грачева Е. Ю. История становления и развития науки финансового права / Е. Ю. Грачева // Очерки финансово-правовой науки современности / под общ. ред. Л. К. Вороновой, Н. И. Химичевой. - Минск ; Харьков : Право, 2011. - 592 с.

2. Колпакова Г. М. Финансы. Денежное обращение. Кредит : учеб. пособие / Г. М. Колпакова. - 2-е изд. перераб. и доп. - М. : Финансы и статистика, 2005. - 496 с.

3. Финансы и кредит : учебник / под ред. М. В. Романовского, Г. Н. Белоглазовой. - М. : Юрайт-Издат, 2003. - 575 с.

4. Бабич А. М. Финансы. Денежное обращение. Кредит : учебник / А. М. Бабич, Л. Н. Павлова. - М. : Юнити-Дана, 2000. - 687 с.

5. Финансовое право : учебник / под ред. Е. А. Ровинского. - М. : Юрид. лит., 1971. - 392 c.

6. Финансовое право Российской Федерации : учебник / отв. ред. М. В. Карасева. - М. : Юристъ, 2002. - 576 с.

7. Финансовое право : учебник / под ред. О. Н. Горбуновой. - 2-е изд., перераб. и доп. М. : Юристъ, 2000. -495 с.

8. Финансовое право : учебник / отв. ред. Н. И. Химичева. - 2-е изд., перераб. и доп. М. : Юристъ, 1999. -600 с.

9. Соколова Э. Д. Правовые основы финансовой системы России / Э. Д. Соколова ; под ред. Е. Ю. Грачевой. - М. : Юриспруденция, 2006. - 112 с.

10. Финансовое право : учебник / К. С. Бельский [и др.] ; под ред. С. В. Запольского. М. : Рос. юрид. образование, 2006. - 640 с.

11. Покачалова Е. В. Публичный долг: теоретические и практические аспекты Российского финансового права : дис. ... д-ра юрид. наук : 12.00.14 / Е. В. Покачалова. - Саратов, 2007. $-602 \mathrm{c}$.

12. Мильгаузен Ф. В. Финансовое право : конспект лекций / Ф. В. Мильгаузен. - М. : Лит. Волкова, 1868. - 112 с.

13. Лебедев В. А. Финансовое право : учебник / В. А. Лебедев ; науч. ред. А. Н. Козырин ; сост., автор коммент. А. А. Ялбулганов. - М. : Статут, 2000. - 461 с.

14. Янжул И. И. Основные начала финансовой науки. Учение о государственных доходах / И. И. Янжул. - 4-е изд. изм. и доп. - СПб., : Тип. Стасюлевича М. М., 1904. - 500 с.

15. Финансы / В. М. Родионова, Ю. Я. Вавилов, Л. И. Гончаренко [и др.]. - М. : Финансы и статистика, $1995 .-432 \mathrm{c}$.

16. Васильева Н. В. Правовое регулирование публичных доходов / Н. В. Васильева. Иркутск : Изд-во БГУЭП, 2015. - 194 с.

17. Дадашев А. З. Финансовая система России : учеб. пособие / А. З. Дадашев, Д. Г. Черник. - М. : Инфра-М, 1997. - 248 с.

18. Советское финансовое право : учебник / под ред. В. В. Бесчеревных, С. Д. Цыпкина. - М. : Юрид. лит., 1982. - 424 c.

\section{Baikal Research Journal}


19. Ашмарина Е. М. Финансово-правовые аспекты учетных систем Российской Федерации : дис. ... д-ра юрид. наук : 12.00.14 / Е. М. Ашмарина. - M, 2006. - 387 с.

20. Ивлиева М. Ф. Значение категории «финансовая деятельность государства» в науке финансового права / М.Ф. Ивлиева // Федеральные и региональные аспекты финансового права : «Круглый стол», посвящ. 75-летию акад. Н. И. Химичевой : тезисы выступлений (2-3 окт. 2003 г.) / под ред. Е. В. Покачаловой. - Саратов : Изд-во ГОУ ВПО «Сарат. гос. акад. права», 2004. - С. 14-16.

21. Соколова Э. Д. Современные проблемы науки финансового права / Э. Д. Соколова // Актуальные проблемы финансового права : сб. науч. ст., посвящ. 75-летию д-ра юрид. наук, проф., акад. Высшей школы РАН Н. И. Химичевой / под ред. Е. В. Покачаловой. - Саратов : Изд-во ГОУ ВПО «Сарат. гос. акад. права», 2003. - С. 22-23.

22. Соколова Э. Д. Теоретические аспекты правового регулирования финансовой деятельности государства и муниципальных образований : дис. ... д-ра юрид. наук : 12.00.14/ Э. Д. Соколова. - М., 2008. - 400 с.

23. Боди 3. Финансы : учеб. пособие : пер. с англ. / З. Боди, Р. Мертон. - М. : Вильямс, 2000. $-592 \mathrm{c}$.

24. Финансы : учебник / под ред. М. В. Романовского, О. В. Врублевской, Б. М. Сабанти. - 2-е изд. перераб. и доп. - М. : Юрайт-Издат, 2006. - 462 с.

25. Сергиенко Я. В. Финансы и реальный сектор / Я. В. Сергиенко. - М. : Финансы и статистика, 2004. - 384 с.

26. Мандрица В. М. Финансовое право / В. М. Мандрица, И. В. Рукавишникова, Д. Н. Дружинин. - Ростов н/Д : Феникс, 1999. - 444 с.

27. Нешитой А. С. Финансы : учебник / А. С. Нешитой. - 7-е изд., перераб. и доп. - М. : Дашков и К, 2007. - 512 с.

28. Ржевская Т. Г. Финансовая система и пропорциональность российского бюджета (теория и практика формирования бюджетных пропорций) : монография / Т. Г. Ржевская. М. : Юнити-Дана : Закон и право, 2008. - 159 с.

29. Комарова Г. В. Финансовая система государства как объект судебной защиты : автореф. дис. ... канд. юрид. наук : 12.00.14 / Г. В. Комарова. - М., 2011. - 20 с.

30. Запольский С. В. Теория финансового права : науч. очерки / С. В. Запольский. - М. : РАП, 2010. - $371 \mathrm{c.}$

31. Саттарова Н. А. Принуждение в финансовом праве : дис. ... д-ра юрид. наук : 12.00.14/ Н. А. Саттарова. - М., 2006. - 493 с.

32. Финансовое право : учебник / под ред. Е. Ю. Грачевой, Г. Н. Толстопятенко. - М. : ТК Велби, 2003. - 536 с.

33. Горбунова О. Н. Проблемы закона о финансах в условиях финансового кризиса / О. Н. Горбунова // Известия Иркутской государственной экономической академии. 2010. — № 1 (69). — С. 125-133.

\section{References}

1. Gracheva E. Yu. History of establishment and development of financial law science. In Voronova L. K., Khimicheva N. I. (eds). Ocherki finansovo-pravovoi nauki sovremennosti [Sketchbook of modern finance-legal science]. Moscow, Khar'kov, Pravo Publ., 2011. 592 p.

2. Kolpakova G. M. Finansy. Denezhnoe obrashchenie. Kredit [Finance. Monetary circulation. Credit]. $2^{\text {nd }}$ ed. Moscow, Finansy i statistika Publ., 2005. 496 p.

3. Romanovsky M. V., Beloglazovy G. N. (eds). Finansy i kredit [Finance and credit]. Moscow, Yurait-Izdat Publ., 2003. 575 p.

4. Babich A. M., Pavlova L. N. Finansy. Denezhnoe obrashchenie. Kredit [Finance. Monetary circulation. Credit]. Moscow, Yuniti-Dana Publ., 2000. 687 p.

5. Rovinsky E. A. (ed.). Finansovoe pravo [Financial law]. Moscow, Yuridicheskaya literature Publ., 1971. 392 p.

6. Karaseva M. V. (ed.). Finansovoe pravo Rossiiskoi Federatsii [Financial law of the Russian Federation]. Moscow, Yurist" Publ., 2002. 576 p.

7. Gorbunova O. N. (ed.). Finansovoe pravo [Financial law]. 2 ${ }^{\text {nd }}$ ed. Moscow, Yurist" Publ., 2000. $495 \mathrm{p}$.

8. Khimicheva N. I. (ed.). Finansovoe pravo [Financial law]. $2^{\text {nd }}$ ed., Moscow, Yurist” Publ., 1999. $600 \mathrm{p}$.

\section{Baikal Research Journal}


9. Sokolova E. D.; Gracheva E. Yu. (ed.). Pravovye osnovy finansovoi sistemy Rossii [Legal basics of Russia's financial system]. Moscow, Yurisprudentsiya Publ., 2006. 112 p.

10. Belsky K. S. et al.; Zapolsky S. V. (ed.). Finansovoe pravo [Financial law]. Moscow, Rossiiskoe yuridicheskoe obrazovanie Publ., 2006. 640 p.

11. Pokachalova E. V. Publichnyi dolg: teoreticheskie i prakticheskie aspekty Rossiiskogo finansovogo prava. Dokt. Diss. [Public debt: theoretical and practical aspects of Russian financial law. Doct. Diss.]. Saratov, 2007. 602 p.

12. Milgauzen F. V. Finansovoe parvo. Konspekt lektsii [Financial law. Notes of lectures]. Moscow, Volkova Publ., 1868. 112 p.

13. Lebedev V. A.; Kozyrin A. N., Yalbulganov A. A. (eds). Finansovoe pravo [Financial law]. Moscow, Statut Publ., 2000. 461 p.

14. Yanzhul I. I. Osnovnye nachala finansovoi nauki. Uchenie o gosudarstvennykh dokhodakh [Basic principles of financial science. Doctrine of public revenue]. ${ }^{\text {th }}$ ed. Saint Petersburg, Stasyulevich M. M. Publ., 1904. 500 p.

15. Rodionova V. M., Vavilov Yu. Ya., Goncharenko L. I. et al. Finansy [Finance]. Moscow, Finansy i statistika Publ., 1995. 432 p.

16. Vasilyeva N. V. Pravovoe regulirovanie publichnykh dokhodov [Legal regulation of public revenue]. Irkutsk, Baikal State University of Economics and Law Publ., 2015. 194 p.

17. Dadashev A. Z., Chernik D. G. Finansovaya sistema Rossii [Russia's financial system]. Moscow, Infra-M Publ., 1997. 248 p.

18. Bescherevnykh V. V., Tsypkin S. D. (eds). Sovetskoe finansovoe parvo [Soviet financial law]. Moscow, Yuridicheskaya literature Publ., 1982. 424 p.

19. Ashmarina E. M. Finansovo-pravovye aspekty uchetnykh sistem Rossiiskoi Federatsii. Dokt. Diss. [Finance-legal aspects of accounting systems of the Russian Federation. Doct. Diss.]. Moscow, 2006. 387 p.

20. Ivliyeva M. F. Meaning of category «financial activity of the state» in the science of financial law. In Pokachalova E. V. (ed.). Federal'nye i regional'nye aspekty finansovogo prava. "Kruglyi stol», posvyashchennyi 75-letiyu akademika N. I. Khimichevoi. Tezisy vystuplenii (2-3 oktyabrya 2003 g.) [Federal and regional aspects of financial law. «Round Table» devoted to 75-th anniversary of academician N. I. Khimicheva. Speaking Notes (October2-3, 2003) Saratov State Academy of Law Publ., 2004, pp. 14-16. (In Russian).

21. Sokolova E. D. Modern problems of science of financial law. In Pokachalova E. V. (ed.). Aktual'nye problemy finansovogo prava. Sbornik nauchnykh statei, posvyashchennykh 75-letiyu doktora yuridicheskikh nauk, professora, akademika Vysshei shkoly RAN N. I. Khimichevoi [Topical problems of financial law. Collection of research articles devoted to 75-th anniversary Doctor habil in Law, Professor, Academician of Higher School of RAS N. I. Khimicheva]. Saratov State Academy of Law Publ., 2003, pp. 22-23. (In Russian).

22. Sokolova E. D. Teoreticheskie aspekty pravovogo regulirovaniya finansovoi deyatel'nosti gosudarstva i munitsipal'nykh obrazovanii. Dokt. Diss. [Theoretical aspects of legal regulation of financial activity of government and municipal entities. Doct. Diss.]. Moscow, 2008. $400 \mathrm{p}$.

23. Bodi Z., Merton R. Finansy [Finance]. Moscow, Vil'yams Publ., 2000. 592 p.

24. Romanovskaya M. V., Vrublevskaya O. V., Sabanti B. M. (eds). Finansy [Finance]. $2^{\text {nd }}$ ed. Moscow, Yurait-Izdat Publ., 2006. 462 p.

25. Sergiyenko Ya. V. Finansy i real'nyi sektor [Finance and real sector]. Moscow, Finansy i statistika Publ., 2004. 384 p.

26. Mandritsa V. M., Rukavishnikova I. V., Druzhinin D. N. Finansovoe pravo [Financial Law]. Rostov-on-Don, Feniks Publ., 1999. 444 p.

27. Neshitoi A. S. Finansy [Finance]. $5^{\text {th }}$ ed. Moscow, Dashkov i K Publ., 2007. 512 p.

28. Rzhevskaya T. G. Finansovaya sistema i proportsional'nost' rossiiskogo byudzheta (teoriya i praktika formirovaniya byudzhetnykh proportsii) [Financial system and proportionality of the Russian budget (theory and practice of forming budget proportions)]. Moscow, Yuniti-Dana Publ., Zakon i pravo Publ., 2008. 159 p.

29. Komarova G. V. Finansovaya sistema gosudarstva kak ob"ekt sudebnoi zashchity. Avtoref. Kand. Diss. [Financial system of the state as an object of judicial protection. Cand. Diss. Thesis]. Moscow, 2011. $20 \mathrm{p}$.

30. Zapol'skii S. V. Teoriya finansovogo prava [Theory of financial law]. Moscow, RAP Publ., 2010. $371 \mathrm{p}$.

\section{Baikal Research Journal}


31. Sattarova N. A. Prinuzhdenie v finansovom prave. Dokt. Diss. [Enforcement in financial law. Doct. Diss.]. Moscow, 2006. 493 p.

32. Gracheva E. Yu., Tolstopyatenko G. P. (eds). Finansovoe pravo [Financial Law]. Moscow, TK Velbi Publ., 2004. 536 p.

33. Gorbunova O. N. Problems of finance law in terms of financial crisis. Izvestiya Irkutskoy gosudarstvennoy ekonomicheskoy akademii = Bulletin of Irkutsk State Economics Academy, 2010, no. 1 (69), pp. 125-133. (In Russian).

\section{Информация об авторе}

Пятковская Юлия Валерьевна - кандидат юридических наук, доцент, кафедра предпринимательского и финансового права, Байкальский государственный университет, 664003, г. Иркутск, ул. Ленина, 11, e-mail: julart@yandex.ru.

\section{Author}

Yuliya V. Pyatkovskya - PhD in Law, Assistant Professor, Chair of Business and Financial Law, Baikal State University, 11 Lenin St., 664003, Irkutsk, Russian Federation; e-mail: julart@yandex.ru.

\section{Библиографическое описание статьи}

Пятковская Ю. В. Финансовая система России как базовая категория финансовой науки и науки финансового права: подходы к определению / Ю. В. Пятковская // Baikal Research Journal. — 2016. — T. 7, № 2. — DOI : 10.17150/2411-6262.2016.7(2).20.

\section{Reference to article}

Pyatkovskaya Yu. V. Russia's financial system as a basic category of financial science and science of financial law: approaches to definition. Baikal Research Journal, 2016, vol. 7, no. 2. DOI: 10.17150/2411-6262.2016.7(2).20. (In Russian).

\section{Baikal Research Journal}

